\title{
The fine-scale genetic structure of the malaria vectors Anopheles funestus and Anopheles gambiae (Diptera: Culicidae) in the north-eastern part of Tanzania
}

\author{
P. Gélin ${ }^{1}$, H. Magalon ${ }^{1}$, C. Drakeley, ${ }^{2,3}$, C. Maxwel1 ${ }^{2,4}$, S. Magesa ${ }^{4}$, \\ W. Takken ${ }^{5}$ and C. Boëte ${ }^{3,5,6 *}$ \\ ${ }^{1}$ UMR ENTROPIE Université de La Réunion/IRD/CNRS, Faculté des Sciences et \\ Technologies, Université de La Réunion, 15 Bd René Cassin, CS 92003, 97744 \\ St Denis Cedex 09, La Réunion, France; ${ }^{2}$ Faculty of Infectious and Tropical \\ Diseases, London School of Hygiene and Tropical Medicine, WC1E 7HT, London, \\ UK; ${ }^{3}$ Joint Malaria Programme, PO Box 2228 Moshi, Tanzania; ${ }^{4}$ Amani Medical \\ Research Centre, National Institute for Medical Research, PO Box 81, Muheza, \\ Tanzania; ${ }^{5}$ Laboratory of Entomology, Wageningen University and Research \\ Centre, PO Box 16, 6700, AA Wageningen, the Netherlands; ${ }^{6} \mathrm{UMR}$ "Emergence \\ des Pathologies Virales", EPV Aix-Marseille Université, IRD 190 - Inserm 1207 - \\ EHESP, 27 Bd Jean Moulin, 13005, Marseille, France
}

\begin{abstract}
Understanding the impact of altitude and ecological heterogeneity at a fine scale on the populations of malaria vectors is essential to better understand and anticipate eventual epidemiological changes. It could help to evaluate the spread of alleles conferring resistance to insecticides and also determine any increased entomological risk of transmission in highlands due to global warming. We used microsatellite markers to measure the effect of altitude and distance on the population genetic structure of Anopheles funestus and Anopheles gambiae s.s. in the Muheza area in the north-eastern part of Tanzania (seven loci for each species). Our analysis reveals strong gene flow between the different populations of An. funestus from lowland and highland areas, as well as between populations of An. gambiae sampled in the lowland area. These results highlight for An. funestus the absence of a significant spatial subpopulation structuring at smallscale, despite a steep ecological and altitudinal cline. Our findings are important in the understanding of the possible spread of alleles conferring insecticide resistance through mosquito populations. Such information is essential for vector control programmes to avoid the rapid spread and fixation of resistance in mosquito populations.
\end{abstract}

\section{Introduction}

Environmental heterogeneity is known to be a driver of population structure (Temunović et al.,

*E-mail: cboete@gmail.com
2012; Stein et al., 2014), and malaria mosquitoes are no exception (Touré et al., 1994). Without doubt, altitude is a major parameter affecting it because of the abiotic (temperature and humidity) as well as the biotic conditions, including the lower presence of pathogens such as Plasmodium spp., as shown in 
bird populations (van Rooyen et al., 2013). As global warming is significantly affecting species distribution as well as their mutual interactions, altitude can be considered as a proxy to understand its impact on the structure of populations of terrestrial insects (Hodkinson, 2005), including mosquitoes. In the case of malaria, the large increase in household ownership of long-lasting insecticidal nets (LLINs) has contributed to an important decrease in the number of malaria cases in the last decade (WHO, 2014), but at the same time, this is associated with a greater risk of the spread of resistance to pyrethroids, the sole insecticidal class used for LLIN treatment (Ranson et al., 2011). Understanding, at a fine scale, how resistance can spread in mosquito populations is of critical importance to optimize current and future vector control. Genetic data can, not only help obtain this information, but can also provide a better understanding of the role of connectivity between populations on the dynamics of disease transmission (Donnelly et al., 2004). Finally, and on a more hypothetical aspect of the control of vector-borne diseases, it is a prerequisite for any release of genetically modified mosquitoes or sterile insects aimed to control the disease at a large scale.

Along the coast of Tanzania, the major malaria vectors are Anopheles funestus and Anopheles gambiae s.s. (Magesa et al., 1991; Temu et al., 1998; Mboera and Magesa, 2001; Maliti et al., 2014). Here, we present a comparative study of the population genetics of these two major vectors from the Muheza district in the north-eastern part of Tanzania, to investigate the spatial population structure of these two anopheline species. This region is a rural area known for its holoendemic transmission of malaria in the lowland area (Mboera and Magesa, 2001; Alilio et al. 2004), and it also presents a steep ecological cline with the presence of highland areas close to the town of Muheza and in the vicinity of the Amani Nature Reserve in the Tanga Region of Tanzania, East Africa.

\section{Materials and methods}

\section{Collection site}

Adult mosquitoes were collected in Muheza district, Tanga Region in the north-eastern part of Tanzania. Six sites were chosen that could be organized in two clusters according to their altitudes: the lowland cluster (mean altitude $=236$ $\mathrm{m} \pm 11.8 \mathrm{~m}$ ) included three villages (Mamboleo, Songa Kibaoni, Zeneth), and the highland area (mean altitude $=952 \mathrm{~m} \pm 63.2 \mathrm{~m}$ ) with three villages (Mikwinini, Mlesa, Ndola) (Fig. 1 and Table 1). Pairwise distances between villages inside each cluster ranged from 5 to $10 \mathrm{~km}$ (Table 2).

\section{Mosquito sampling, species identification and oocysts collection}

The collections were performed between May 2005 and August 2005 where indoor-resting bloodfed anopheline females were collected with aspirators in the morning regularly during this period, i.e. between 15 and 19 times in the lowland and the highland areas, respectively. At each visit, the same four houses were visited for 15 to $20 \mathrm{~min}$ in each village. Mosquitoes were brought to the insectary in Muheza, fed with a sugar solution ad libitum, and maintained for 7 days in small pots. On the seventh day after capture, midguts of the surviving mosquitoes were dissected with tweezers under a light microscope and the presence/absence of Plasmodium falciparum oocysts recorded. All the collected mosquitoes did not survive the period of 7 days in the insectary. Performing an analysis of the mortality rate neither revealed any significant differences between areas and species, nor their interactions (see Additional File 1). This reveals the absence of any bias in the mortality. Similarly, a number of mosquitoes survived the period of 7 days in the insectary, but they were untested for genotyping (conservation issues). Again the statistical analysis (see Additional File 2) revealed no significant difference between the groups, and this did not affect the survey.

Morphological identification based on the taxonomic keys for the identification of Afrotropical mosquitoes (Gillies and de Meillon, 1968; Gillies and Coetzee, 1987) was done to identify An. funestus group and An. gambiae s.l. DNA extraction from whole insects was performed using the DNeasy Blood and Tissue kit (Qiagen) according to the manufacturer's instructions and DNA concentration was measured with a Nanodrop ${ }^{\circledR}$ spectrophotometer. Identification of subspecies inside each complex was performed by polymerase chain reaction (PCR) according to a protocol based on Koekemoer et al. (2002) within the An. funestus group and Wilkins et al. (2006) within the An. gambiae complex. Sampling details are summarized in Table 1.

\section{Microsatellite genotyping}

A total of 142 An. funestus were genotyped using 10 microsatellite loci: AF2, AF3, AF5, AF19, AF20 (Sinkins et al., 2000), FunF, FunG, FunL, FunO, FunR (Cohuet et al., 2002). A total of 181 An. gambiae individuals were genotyped using 13 microsatellite loci: 11 loci from Zheng et al. (1996) [H29, H46, H88, H131, H143, H197, H249, H555, H675, H678, H1D1 (abbreviated names from Midega et al. (2010)] and two microsatellite loci from the NOS and cecropin $3^{\prime}$ UTR genes (Luckhart et al., 2003), which function in the innate immune system of insects. 


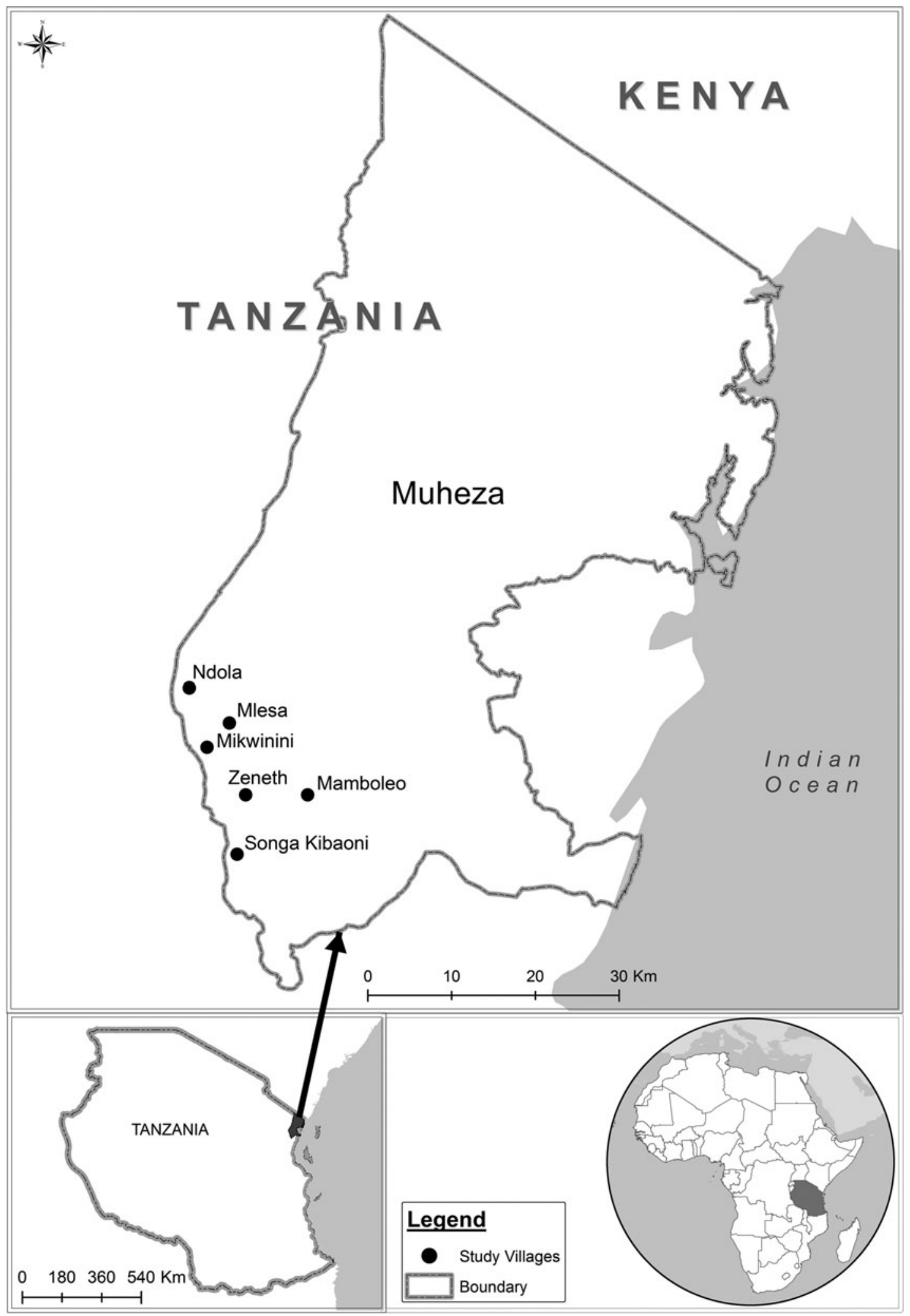

Fig. 1. Map of the area where collections of malaria mosquitoes were performed. 
Table 1. Number of collected adult (Anopheles funestus and An. gambiae) surviving 7 days after collection and their infection status

\begin{tabular}{|c|c|c|c|c|c|c|c|c|}
\hline Species & Village & Latitude & Longitude & $\begin{array}{l}\text { Altitude } \\
\text { (m) }\end{array}$ & $\begin{array}{l}\text { Area of } \\
\text { collection } \\
\text { (altitude) }\end{array}$ & $\begin{array}{l}\text { Number of } \\
\text { collected } \\
\text { mosquitoes }\end{array}$ & $\begin{array}{l}\text { Number of } \\
\text { surviving } \\
\text { mosquitoes } \\
\text { after } 7 \text { days }\end{array}$ & $\begin{array}{c}\text { Number of } \\
\text { mosquitoes } \\
\text { used in the } \\
\text { genetic } \\
\text { analysis }\end{array}$ \\
\hline \multirow[t]{4}{*}{ An. funestus } & Ndola & $\mathrm{S} 05^{\circ} 06.400^{\prime}$ & E $038^{\circ} 34.325^{\prime}$ & $1060 \mathrm{~m}$ & Highland & 129 & 40 & 28 \\
\hline & Mlesa & $\mathrm{S} 05^{\circ} 07.921^{\prime}$ & E $038^{\circ} 37.365^{\prime}$ & $845 \mathrm{~m}$ & Highland & 16 & 9 & 4 \\
\hline & Songa Kibaoni & S $05^{\circ} 15.204^{\prime}$ & E $038^{\circ} 38.639^{\prime}$ & $259 \mathrm{~m}$ & Lowland & 20 & 6 & 4 \\
\hline & Zeneth & S $05^{\circ} 13.492^{\prime}$ & E $038^{\circ} 39.620^{\prime}$ & $229 \mathrm{~m}$ & Lowland & 616 & 176 & 103 \\
\hline \multirow[t]{3}{*}{ An. gambiae } & Ndola & $\mathrm{S} 05^{\circ} 06.400^{\prime}$ & E $038^{\circ} 34.325^{\prime}$ & $1060 \mathrm{~m}$ & Highland & 42 & 14 & - \\
\hline & Mlesa & $\mathrm{S} 05^{\circ} 07.921^{\prime}$ & E $038^{\circ} 37.365^{\prime}$ & $845 \mathrm{~m}$ & Highland & 11 & 8 & - \\
\hline & Mamboleo & $\mathrm{S} 05^{\circ} 13.123^{\prime}$ & E $038^{\circ} 43.244^{\prime}$ & $220 \mathrm{~m}$ & Lowland & 126 & 66 & 43 \\
\hline
\end{tabular}

Table 2. Matrix of pairwise geographic distance amongst sampled sites. Distances are expressed in $\mathrm{km}$

\begin{tabular}{lrlllll}
\hline & \multicolumn{2}{c}{ Highland } & & \multicolumn{3}{c}{ Lowland } \\
\cline { 2 - 3 } \cline { 6 - 7 } & Ndola & Mlesa & & Zeneth & Songa Kibaoni & Mamboleo \\
\hline Mlesa & 6.0 & - & & & \\
Zeneth & 16.4 & 11.3 & & & & \\
Songa Kibaoni & 17.9 & 13.5 & & 3.5 & - & - \\
Mamboleo & 20.5 & 15.5 & & 6.5 & 9.2 & - \\
\hline
\end{tabular}

For each species, the forward primer of each locus was labelled with a fluorescent dye using a M13 labelled tail added to the 5'-end of the oligonucleotide (four colours: FAM, VIC, NED, PET). PCR were performed in a volume of $10 \mu \mathrm{l}$ with $5 \mu \mathrm{l}$ of MasterMix 2x (Applied Biosystems ${ }^{\mathrm{TM}}$; Thermo Fisher Scientific Inc., Waltham, Massachusetts, USA), $0.25 \mu \mathrm{l}$ of each primer $(10 \mu \mathrm{M})$ and $0.25 \mu \mathrm{l}$ of labelled M13 tail $(10 \mu \mathrm{M}), 2 \mu \mathrm{l}$ of DNA template $(10 \mathrm{ng} / \mu \mathrm{l})$ using the following cycling: 2 min at $95^{\circ} \mathrm{C}$; followed by 30 cycles of $30 \mathrm{sec}$ at $95^{\circ} \mathrm{C}, 30 \mathrm{sec}$ at $55^{\circ} \mathrm{C}$ and $30 \mathrm{sec}$ at $72{ }^{\circ} \mathrm{C}$ ); then $5 \mathrm{~min}$ at $95^{\circ} \mathrm{C}$. Mixes of PCR products were then made according to amplicon size and dye, and genotyping was performed using an ABI PRISM 3730 XL DNA sequencer (Applied Biosystems ${ }^{\mathrm{TM}}$ ). Results were analysed with GeneMapper ${ }^{\mathrm{TM}}$ v. 4.0 software (Applied Biosystems ${ }^{\mathrm{TM}}$ ).

\section{Data analyses}

Estimates of linkage disequilibrium were performed using FSTAT v. 2.9.3 (Goudet, 1995). The presence of null alleles was assessed using MICROCHECKER v. 2.2.3 (Van Oosterhout et al., 2004).

Genetic diversity of mosquito populations was assessed by the number of alleles $(\mathrm{Na})$, observed heterozygosity $\left(H_{O}\right)$, and expected heterozygosity $\left(H_{E}\right)$ using Arlequin v. 3.5.1.2 (Excoffier et al., 2005). Tests of deviation from Hardy-Weinberg equilibrium (HWE) were performed using FSTAT v. 2.9.3 (Goudet, 1995).

The significance of genetic differentiation between populations based on allelic distribution across populations was examined using a Fisher exact test with FSTAT v. 2.9.3 (Goudet, 1995). The pairwise $F_{\text {ST }}$ statistic between populations was calculated after Weir and Cockerham (1984) using FSTAT v. 2.9.3 (Goudet, 1995) and Arlequin v. 3.5.1.2 (Excoffier et al., 2005).

For each species, without taking into account their geographic origin, An. funestus and $A n$. gambiae individuals were clustered on the basis of their genetic relatedness using the Bayesian clustering approach implemented in STRUCTURE V. 2.3.3 (Pritchard et al., 2000; Falush et al., 2003). Simulations were performed using the admixture and correlated frequencies model. We estimated the number $K$ of genetic clusters (here between $K=$ 1 and $K=4$ ) to which the individuals should be assigned. For all simulations, we did not force the model with predefined allele frequencies for source clusters. Five independent runs were conducted to assess the consistency of the results across runs, 
Table 3. Summary statistics of Anopheles funestus populations

\begin{tabular}{|c|c|c|c|c|c|c|}
\hline Population & $N$ & $N_{a}$ & $H_{O}$ & $H_{E}$ & $F_{I S}$ & $r$ \\
\hline \multicolumn{7}{|l|}{ Highland } \\
\hline AF2 & 30 & 9 & 0.600 & 0.785 & 0.239 & 0.11 (yes) \\
\hline AF19 & 31 & 6 & 0.645 & 0.555 & -0.165 & -0.14 (no) \\
\hline AF20 & 29 & 3 & 0.552 & 0.639 & 0.138 & 0.07 (no) \\
\hline FunF & 28 & 4 & 0.429 & 0.442 & 0.031 & -0.01 (no) \\
\hline FunG & 30 & 4 & 0.733 & 0.629 & $-0.170^{* *}$ & -0.13 (no) \\
\hline FunO & 31 & 5 & 0.484 & 0.526 & 0.081 & 0.03 (no) \\
\hline FunR & 32 & 4 & 0.406 & 0.496 & 0.183 & 0.08 (no) \\
\hline All & 32 & $5 \pm 2$ & $0.550+0.120$ & $0.583+0.110$ & 0.056 & \\
\hline \multicolumn{7}{|l|}{ Lowland } \\
\hline AF2 & 110 & 11 & 0.718 & 0.824 & $0.129^{* *}$ & 0.06 (yes) \\
\hline AF19 & 107 & 6 & 0.411 & 0.503 & $0.183^{* *}$ & 0.10 (yes) \\
\hline AF20 & 106 & 4 & 0.396 & 0.542 & $0.268^{* * *}$ & 0.12 (yes) \\
\hline FunF & 107 & 5 & 0.579 & 0.603 & 0.040 & 0.01 (no) \\
\hline FunG & 106 & 6 & 0.651 & 0.725 & $0.102^{* * *}$ & 0.04 (no) \\
\hline FunO & 108 & 6 & 0.565 & 0.569 & 0.008 & 0.00 (no) \\
\hline FunR & 105 & 4 & 0.305 & 0.505 & $0.400^{* * *}$ & 0.18 (yes) \\
\hline All & 110 & $6 \pm 2.38$ & $0.518+0.150$ & $0.610+0.121$ & $0.151^{* *}$ & \\
\hline
\end{tabular}

$N$ : number of amplified individuals; $N_{A}$ : number of alleles; $H_{O}$ : observed heterozygosity; $H_{E}$ : expected heterozygosity under Hardy-Weinberg equilibrium; $F_{I S}$ : inbreeding coefficient. Next to the $F_{I S}$ is indicated the significance of the $P$-values for deviation to Hardy-Weinberg equilibrium: ${ }^{*}: P<0.05$; ${ }^{* *}: P<0.01$; ${ }^{* * *}: P<0.001 ; r$ : Null allele frequencies (presence or absence is indicated next by yes or no).

and all runs were based on $10^{6}$ iterations after a burn-in period of $10^{5}$ iterations. We then identified the number of genetically homogeneous clusters as described by Evanno et al. (2005).

As analyses using STRUCTURE are based on strong assumptions (Panmixia, no linkage disequilibrium), we performed a dissimilarity analysis calculating the Shared Allele Distance (DAS) between pairs of genotypes and drawing a neighbour-joining tree with DARwin v 5.0 (Perrier and Jacquemoud-Collet, 2006).

\section{Results}

\section{Species identification}

Of the 142 An. funestus individuals, all were identified as An. funestus sensu stricto following PCR identification tests. Amongst 181 An. gambiae individuals, 172 were identified as An. gambiae sensu stricto and nine as An. arabiensis. Anopheles arabiensis were excluded from further analyses.

\section{Linkage disequilibrium and test for Hardy-Weinberg equilibrium}

Due to a large number of missing data for some of the loci, which may be due to null alleles, data from seven microsatellite loci from 10 were retained for further analyses for An. funestus (AF2, AF19, AF20, FunF, FunG, FunO and FunL). Amongst 21 linkage equilibrium tests, none was significant at the $5 \%$ level after Bonferroni correction for multiple testing. As such, these seven loci were considered as independent and kept for further analyses. Because of small sampling size for some locations and low Plasmodium prevalence over the dates of collection, all individuals were pooled into two populations: 'Highland' $(n=32)$ and 'Lowland' $(n=110)$.

For An. gambiae, due to a large number of missing data for some of the loci, which may also be due to null alleles, data from seven microsatellite loci from 13 were retained for further analyses (H29, H88, H131, H249, H678, H1D, NOS). Amongst 21 linkage equilibrium tests, none was significant at the $5 \%$ level after Bonferroni correction for multiple testing. As such, these seven loci were considered as independent and kept for further analyses. Due to low Plasmodium prevalence, infected individuals were pooled with non-infected for each village. For An. gambiae, the term 'population' referred to individuals sampled in the same village during the time of the experiment.

Regarding the two An. funestus populations, the highland population did not show deviation from Hardy-Weinberg equilibrium over all loci, whilst the lowland population showed a significant excess of homozygotes ( $F_{I S}=0.151^{* *}$; Table 3 ). Additionally, the three populations of An. gambiae showed significant excess of homozygotes over all loci $\left(F_{I S}\right.$ ranged from $0.162^{* *}$ to $0.179^{* *}$; Table 4$)$. 
Table 4. Summary statistics of Anopheles gambiae populations

\begin{tabular}{lrccccc}
\hline Population & $N$ & $N_{a}$ & $H_{O}$ & $H_{E}$ & $F_{I S}$ & $r$ \\
\hline Zeneth & & & & & & \\
H29 & 98 & 6 & 0.255 & 0.320 & $0.205^{* *}$ & 0.08 (yes) \\
H88 & 99 & 7 & 0.364 & 0.656 & $0.436^{* * *}$ & 0.20 (yes) \\
H249 & 100 & 7 & 0.630 & 0.686 & $0.077^{* *}$ & 0.03 (no) \\
H1D1 & 101 & 2 & 0.465 & 0.487 & 0.044 & 0.02 (no) \\
H131 & 98 & 6 & 0.633 & 0.728 & $0.130^{*}$ & 0.06 (yes) \\
H678 & 100 & 11 & 0.790 & 0.806 & 0.021 & 0.01 (no) \\
NOS & 100 & 9 & 0.300 & 0.511 & $0.414^{* * *}$ & 0.19 (yes) \\
All & $\mathbf{1 0 2}$ & $\mathbf{6 . 8} \pm \mathbf{2 . 8}$ & $\mathbf{0 . 4 9 1} \pm \mathbf{0 . 2 0 0}$ & $\mathbf{0 . 5 9 8} \pm \mathbf{0 . 1 6 7}$ & $\mathbf{0 . 1 7 8 ^ { * * }}$ & \\
Songa Kibaoni & & & & & & \\
H29 & 26 & 3 & 0.308 & 0.370 & 0.172 & 0.07 (no) \\
H88 & 22 & 6 & 0.455 & 0.644 & $0.285^{*}$ & 0.13 (no) \\
H249 & 24 & 7 & 0.583 & 0.682 & 0.136 & 0.06 (no) \\
H1D1 & 27 & 2 & 0.444 & 0.453 & 0.019 & 0.00 (no) \\
H131 & 21 & 5 & 0.571 & 0.723 & 0.223 & 0.11 (no) \\
H678 & 23 & 9 & 0.739 & 0.778 & 0.051 & 0.00 (no) \\
NOS & 24 & 6 & 0.250 & 0.430 & $0.424^{*}$ & 0.16 (yes) \\
All & $\mathbf{2 7}$ & $\mathbf{5 . 4} \pm \mathbf{2 . 4}$ & $\mathbf{0 . 4 7 9} \pm \mathbf{0 . 1 6 9}$ & $\mathbf{0 . 5 8 3} \pm \mathbf{0 . 1 6 2}$ & $\mathbf{0 . 1 7 9 * *}$ & \\
Mamboleo & & & & & & \\
H29 & 43 & 3 & 0.302 & 0.285 & -0.062 & -0.02 (no) \\
H88 & 43 & 7 & 0.372 & 0.554 & $0.331^{* *}$ & 0.14 (yes) \\
H249 & 41 & 7 & 0.585 & 0.778 & 0.248 & 0.12 (yes) \\
H1D1 & 43 & 2 & 0.488 & 0.502 & 0.026 & 0.01 (no) \\
H131 & 40 & 7 & 0.525 & 0.682 & 0.242 & 0.11 (yes) \\
H678 & 41 & 8 & 0.756 & 0.813 & 0.071 & 0.03 (no) \\
NOS & 41 & 5 & 0.341 & 0.396 & 0.140 & 0.06 (no) \\
All & 43 & $\mathbf{5 . 6} \pm \mathbf{2 . 3}$ & $\mathbf{0 . 4 8 2} \pm \mathbf{0 . 1 5 9}$ & $\mathbf{0 . 5 7 3} \pm \mathbf{0 . 1 9 6}$ & $\mathbf{0 . 1 6 2 * *}$ & \\
\hline N & & & & & \\
\hline
\end{tabular}

$N$ : number of amplified individuals; $N_{A}$ : number of alleles; $H_{O}$ : observed heterozygosity; $H_{E}$ : expected heterozygosity under Hardy-Weinberg equilibrium; $F_{I S}$ : inbreeding coefficient. Next to the $F_{I S}$ is indicated the significance of the $P$-values for deviation to Hardy-Weinberg equilibrium: *: $P<0.05$; $^{* *}: P<0.01{ }^{* * *}: P<0.001 ; r$ : Null allele frequencies (presence or absence is indicated next by yes or no).

\section{Genetic diversity and population differentiation}

The number of alleles per locus ranged from four (AF20) to 12 (AF2) for An. funestus and from two (H1D1) to 11 (H678) for An. gambiae (Tables 3 and 4, respectively).

Tests of genetic differentiation between populations were performed for each species. For $A n$. funestus, the highland population was undifferentiated from the lowland population $\left(F_{S T}=0.012\right.$, $P=0.05$; Fisher exact test not significant). Moreover, allelic richness of the highland population was not significantly different from the lowland population (permutation test, $P=0.67$ ).

For An. gambiae, the allelic richness of the three populations was not significantly different from each other (permutation test, all $P>0.05$ ). $F_{S T}$ estimates were not significantly different from 0 (Table 5). Thus, no genetic differentiation was found between the three populations, nor when considering only the NOS locus implied in the
Table 5. Pairwise multilocus estimates of $F_{S T}$ for Anopheles gambiae populations. All comparisons for Fisher exact tests were not significant at the 0.05 level

\begin{tabular}{lll}
\hline & Mamboleo & Songa Kibaoni \\
\hline Songa Kibaoni & $0.003^{\mathrm{NS}}$ & - \\
Zeneth & $0.001^{\mathrm{NS}}$ & $0.009^{\mathrm{NS}}$ \\
\hline
\end{tabular}

immune response $\left(F_{S T}\right.$ ranged from 0.001 to 0.018 , all $P>0.05)$.

\section{Assignment tests}

A Bayesian clustering analysis was performed using STRUCTURE. For both An. funestus and An. gambiae, the clustering analysis indicated that the posterior distribution of the allele frequencies amongst clusters was best explained with a grouping into 
(a)

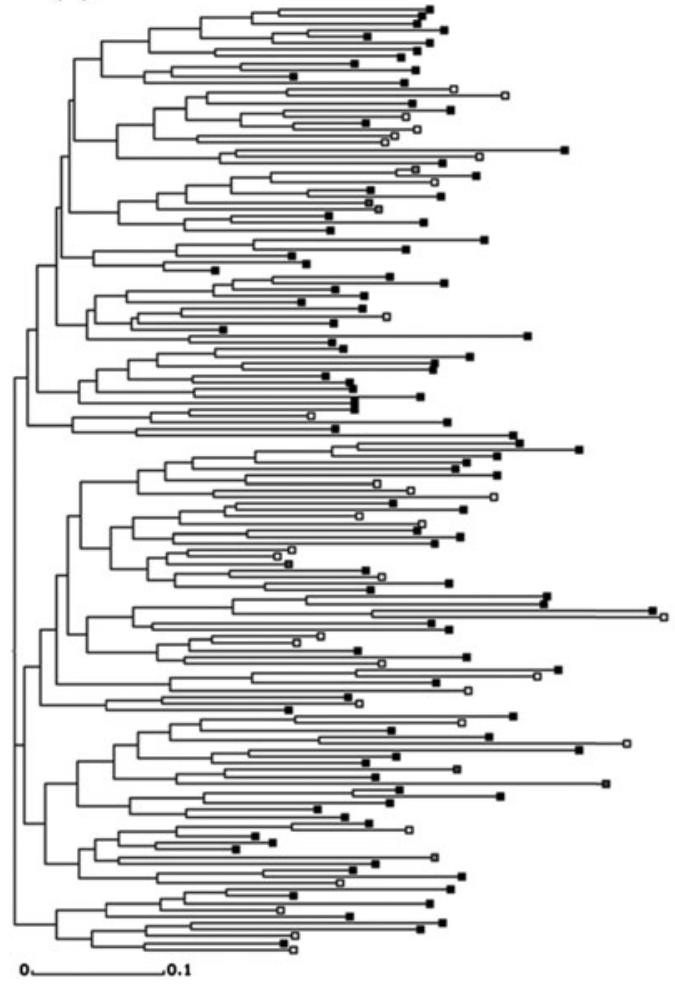

(b)

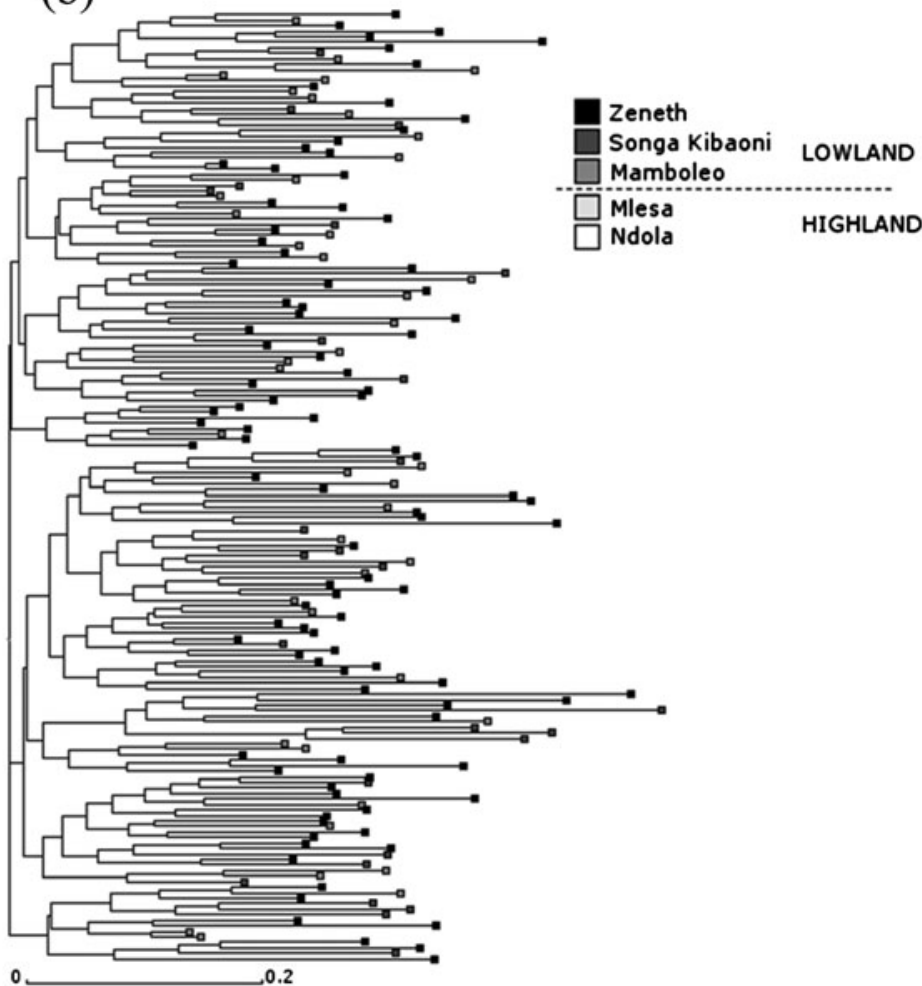

Fig. 2. Neighbour joining trees based on shared allele distance (DAS) for each species. (a) Anopheles funestus and (b) Anopheles gambiae.

$K=1$ genetic cluster (data not shown). This is confirmed by the construction of a neighbourjoining tree based on DAS between pairs of multilocus genotypes for each species. Indeed, neither different genetic clusters nor spatial clustering for both species could be observed (Fig. 2a and b).

\section{Discussion}

\section{Low prevalence of Plasmodium}

We could not perform tests to assess genetic differentiation between 'infected' and 'uninfected' individuals due to the low prevalence found, but it is interesting to note that all infected mosquitoes (10 An. gambiae and six An. funestus) were caught in the lowland, suggesting that altitude could be a structuring factor for immunity gene. We should, however, remain cautious as temperature in altitude could also preclude Plasmodium infection. This would then release the pressure favouring a stronger immune response against malaria parasites. Obviously, we have no information about a potential higher mortality in the infected mosquitoes that were collected but died before dissection 7 days after capture.

\section{High gene flow between populations}

Our results showed that the highland population of An. funestus was not genetically differentiated from the lowland population. We had hypothesized that differences, both in altitude and in ecological factors, could lead to significant genetic differentiation, but this does not appear to be true despite a steep ecological cline. This is important because it shows that altitude does not act as a strong barrier to gene flow.

Likewise, for An. gambiae, the populations were not significantly differentiated from each other in the lowland area (pairwise distances ranged from 3 to $9 \mathrm{~km}$; Table 2). This is consistent with previous studies that have revealed a deme size greater than $50 \mathrm{~km}$ for An. gambiae (Lehmann et al., 1996; Kamau et al., 1998). The similarity between topography and climate of the different locations probably explains this lack of differentiation.

Furthermore, the high positive $F_{I S}$ found for both species could be explained by the presence of null alleles or by the Wahlund effect, either spatial (pool of individuals originated from different houses or different foci within houses) and/or temporal (pool of successive cohorts over a 4-month sampling period). One could suggest that we pooled partially 
diverging clades from An. funestus (Michel et al., 2005), but this hypothesis can be rejected as this should have been revealed by the Bayesian assignment tests. The hypothesis of possible local scale and/or temporal genetic heterogeneity cannot be ruled out. This is, however, not in contradiction with our result of an absence of genetic differentiation at a larger scale, as already found in other organisms (Torda et al., 2013; Gorospe et al., 2013, 2015). To test for local structure, the sampling and genotyping efforts (number of individuals and number of loci) should be enhanced for the different houses and foci to allow fine-scale structuring analyses.

Nevertheless, for both An. funestus and $A n$. gambiae, this is a major point of concern when monitoring the spread of resistance against insecticides, as well as the resistance against drugs in Plasmodium. In a more hypothetical way, such high gene flow between locations presenting different ecological conditions would facilitate the spread of a genetic mutation. The lack of ecological barriers could be an advantage in the use of genetically modified mosquitoes for malaria control (Boëte, 2006; Levy, 2007; Wang and Jacobs-Lorena, 2013).

\section{Conclusion}

Our study found evidence of high gene flow between populations of malaria vectors in northeastern Tanzania. In the case of An. funestus, the genetic structure is unaffected by altitude, at least in this part of East Africa. However, it might be a factor influencing $A n$. gambiae distribution with a decrease of mosquito number as altitude increases. Moreover, and given the importance of the spatio-temporal dynamics of vectors in disease transmission (Chaves et al., 2015), there is a crucial need to understand such vector population dynamics in areas with contrasted patterns of transmission (Kamugisha, 2005), to better design tailor-made solutions to control disease transmission.

\section{Ethics}

The study received ethical approval by the Tanzanian Commission for Science and Technology (COSTECH) with research permit number 2005-51NA-2004-53 granted to C.B. All anopheline collections were undertaken following verbal consent of householders.

\section{Supplementary material}

To view supplementary material for this article, please visit http://dx.doi.org/10.1017/ S1742758416000175.

\section{Acknowledgements}

We are grateful to the team of entomologists for their dedication during the fieldwork and to the villagers who kindly accepted our regular visits in their homes. We thank the GENTYANE platform (INRA, Clermont, France) for their technical support for genotyping. During this work, CB was supported by a Marie Curie Intra-European Fellowship MEIF-CT-2003-501659 at Wageningen University, the Netherlands.

\section{References}

Alilio M. S., Kitua A., Njunwa K., Medina M., Rønn A.M., Mhina J., Msuya F., Mahundi J., Depinay J. M., Whyte S., Krasnik A. and Bygbjerg I. C. (2004) Malaria control at the district level in Africa: The case of the Muheza District in Northeastern Tanzania. American Journal of Tropical Medicine and Hygiene 71(2 Suppl), 205213.

Boëte C. and Joint Malaria Programme, KCMC, Tanzania (2006) Genetically Modified Mosquitoes for Malaria Control, http:/ / www.landesbioscience.com. ISBN: 1-58706-096-5.

Chaves L. F., Imanishi N. and Hoshi T. (2015) Population dynamics of Armigeres subalbatus (Diptera: Culicidae) across a temperate altitudinal gradient. Bulletin of Entomological Research 105, 589-597. doi: 10.1017/S0007485315000474.

Cohuet A., Simard F., Berthomieu A., Raymond M., Fontenille D. and Weill M. (2002) Isolation and characterization of microsatellite DNA markers in the malaria vector Anopheles funestus. Molecular Ecology Notes 2, 498-500. doi: 10.1046/j.1471-8286.2002.00290.x.

Donnelly M. J., Pinto J., Girod R., Besansky N. J. and Lehmann T. (2004) Revisiting the role of introgression vs shared ancestral polymorphisms as key processes shaping genetic diversity in the recently separated sibling species of the Anopheles gambiae complex. Heredity 92, 61-68. doi:10.1038/sj.hdy.6800377.

Evanno G., Regnaut S. and Goudet J. (2005) Detecting the number of clusters of individuals using the software STRUCTURE: A simulation study. Molecular Ecology 14, 2611-2620.

Excoffier L., Laval G. and Schneider S. (2005) Arlequin (Version 3.0): An integrated software package for population genetics data analysis. Evolutionary Bioinformatics 1, 47-50.

Falush D., Stephens M. and Pritchard J. K. (2003) Inference of population structure using multilocus genotype data: Linked loci and correlated allele frequencies. Genetics 164, 1567-1587.

Gillies M. T. and Coetzee M. (1987) A Supplement to the Anophelinae of Africa South of Sahara (Afrotropical Region). South African Institute for Medical Research, Johannesburg, South Africa. 143 pp. 
Gillies M. T. and De Meillon B. (1968) The Anophelinae of Africa South of the Sahara (Ethiopian Zoogeographical Region). South African Institute for Medical Research, Johannesburg, South Africa. 343 pp.

Gorospe K. D. and Karl S. A. (2013) Genetic relatedness does not retain spatial pattern across multiple spatial scales: Dispersal and colonization in the coral, Pocillopora damicornis. Molecular Ecology 22, 3721-3736. doi:10.1111/mec.12335.

Gorospe K. D. and Karl S. A. (2015) Depth as an organizing force in Pocillopora damicornis: Intrareef genetic architecture. PLOS ONE 10, e0122127. doi:10.1371/journal.pone.0122127.

Goudet J. (1995) FSTAT (Version 1.2): A computer program to calculate F-Statistics. Journal of Heredity 86, 485-486.

Hodkinson I. D. (2005) Terrestrial insects along elevation gradients: Species and community responses to altitude. Biological Reviews 80, 489-513. doi:10.1017/S1464793105006767.

Kamau L., Lehmann T., Hawley W. A., Orago A. S. and Collins F.H. (1998) Microgeographic genetic differentiation of Anopheles gambiae mosquitoes from Asembo bay, western Kenya: A comparison with Kilifi in coastal Kenya. The American Journal of Tropical Medicine and Hygiene 58, 64-69.

Kamugisha M. L., Maxwell C. and Curtis C. F. (2005) Characteristics of malaria among children living in lowlands and highlands of Muheza District, north-east Tanzania. Tanzania Health Research Bulletin 7, 67-72.

Koekemoer L. L., Kamau L., Hunt R. H. and Coetzee M. (2002) A cocktail polymerase chain reaction assay to identify members of the Anopheles funestus (Diptera: Culicidae) group. The American Journal of Tropical Medicine and Hygiene 66, 804-811.

Lehmann T., Hawley W. A., Kamau L., Fontenille D., Simard F. and Collins F. H. (1996) Genetic differentiation of Anopheles gambiae populations from East and West Africa: Comparison of microsatellite and allozyme loci. Heredity 77, 192-208.

Levy S. (2007) Mosquito modifications: New approaches to controlling malaria. BioScience 57, 816-821. doi:10.1641/B571003.

Luckhart S., Li K., Dunton R., Lewis E. E., Crampton A. L., Ryan J. R. and Rosenberg R. (2003) Anopheles gambiae immune gene variants associated with natural Plasmodium infection. Molecular and Biochemical Parasitology 128, 83-86. doi: 10.1016/S0166-6851(03)00016-1.

Magesa S. M., Wilkes T. J., Mnzava A. E., Njunwa K. J., Myamba J., Kivuyo M. D., Hill N., Lines J. D. and Curtis C. F. (1991) Trial of pyrethroid impregnated bednets in an area of Tanzania holoendemic for malaria. Part 2. Effects on the malaria vector population. Acta Tropica 49, 97-108.

Maliti D., Ranson H., Magesa S., Kisinza W., Mcha J., Haji K., Killeen G. and Weetman D. (2014) Islands and stepping-stones: Comparative population structure of Anopheles gambiae sensu stricto and Anopheles arabiensis in Tanzania and implications for the spread of insecticide resistance. PLOS ONE 9(10), e110910. doi:10.1371/journal.pone.0110910.

Mboera L. and Magesa S. (2001) The rise and fall of malarial sporozoite rates in Anopheles gambiae s.l. and An. funestus in north-eastern Tanzania, between 1934 and 1999. Annals of Tropical Medicine E Parasitology 95, 325-330.

Michel A. P., Guelbeogo W. M., Grushko O., Schemerhorn B. J., Kern M., Willard M. B., Sagnon N'F., Costantini C. and Besansky N. J. (2005) Molecular differentiation between chromosomally defined incipient species of Anopheles funestus. Insect Molecular Biology 14, 375-387. doi: 10.1111/j.1365-2583.2005.00568.x.

Midega J. T., Muturi E. J., Baliraine F. N., Mbogo C. M., Githure J., Beier J. C. and Yan G. (2010) Population structure of Anopheles gambiae along the Kenyan coast. Acta Tropica 114, 103-108. doi:10.1016/j.actatropica.2010.01.011.

Perrier X. and Jacquemoud-Collet J. P. (2006) DARwin Software v 5.0. http:/ / darwin.cirad.fr/.

Pritchard J. K., Stephens M. and Donnelly P. (2000) Inference of population structure using multilocus genotype data. Genetics 155, 945-959.

Ranson H., N'guessan R., Lines J., Moiroux N., Nkuni Z. and Corbel V. (2011) Pyrethroid resistance in African anopheline mosquitoes: What are the implications for malaria control? Trends in Parasitology 27, 91-98.

Sinkins S. P., Hackett B. J., Costantini C., Vulule J., Ling Y.-Y., Collins F. H. and Besansky N. J. (2000) Isolation of polymorphic microsatellite loci from the malaria vector Anopheles funestus. Molecular Ecology 9, 490-492. doi:10.1046/j.1365-294x.2000.00871-2.

Stein A., Gerstner K. and Kreft H. (2014) Environmental heterogeneity as a universal driver of species richness across taxa, biomes and spatial scales. Ecology Letters $17,866-880$.

Temu E. A., Minjas J. N., Coetzee M., Hunt R. H. and Shiff C. J. (1998) The role of four anopheline species (Diptera: Culicidae) in malaria transmission in coastal Tanzania. Transactions of the Royal Society of Tropical Medicine and Hygiene 92, 152-158.

Temunović M., Franjić J., Satovic Z., Grgurev M., Frascaria-Lacoste N. and Fernández-Manjarrés J. F. (2012) Environmental heterogeneity explains the genetic structure of continental and Mediterranean populations of Fraxinus angustifolia Vahl. PLOS ONE 7(8), e42764. doi:10.1371/journal.pone.0042764.

Torda G., Lundgren P., Willis B. L. and van Oppen M. J. H. (2013) Revisiting the connectivity puzzle of the common coral Pocillopora damicornis. Molecular Ecology 22, 5805-5820. doi:10.1111/mec.12540.

Touré Y. T., Petrarca V., Traoré S. F., Coulibaly A., Maïga H. M., Sankaré O., Sow M., Di Deco M. A. and Coluzzi M. (1994) Ecological genetic studies in the chromosomal form Mopti of Anopheles gambiae s.str. in Mali, West Africa. Genetica 94, 213-223.

Van Oosterhout C., Hutchinson W. F., Wills D. P. M. and Shipley P. (2004) Micro-checker: Software for 
identifying and correcting genotyping errors in microsatellite data. Molecular Ecology Notes 4, 535-538.

van Rooyen J., Lalubin F., Glaizot O. and Christe P. (2013) Altitudinal variation in haemosporidian parasite distribution in great tit populations. Parasites $\mathcal{E}$ Vectors 6, 139. doi: 10.1186/1756-3305-6-13.

Wang S. and Jacobs-Lorena M. (2013) Genetic approaches to interfere with malaria transmission by vector mosquitoes. Trends in Biotechnology 31, 185-193. doi: 10.1016/j.tibtech.2013.01.001.

Weir B. S. and Cockerham C. (1984) Estimating F-statistics for the analysis of population structure. Evolution 38, 1358-1370.
WHO [World Health Organization] (2014) World Malaria Report 2014. World Health Organization, Geneva, Switzerland. 242 pp. ISBN: 9789241564830.

Wilkins E. E., Howell P. I. and Benedict M. Q. (2006) IMP PCR primers detect single nucleotide polymorphisms for Anopheles gambiae species identification, Mopti and Savanna rDNA types, and resistance to dieldrin in Anopheles arabiensis. Malaria Journal 5, 125. doi: 10.1186/1475-2875-5-125.

Zheng L., Benedict M. Q., Cornel A. J., Collins F. H. and Kafatos F. C. (1996) An integrated genetic map of the African human malaria vector mosquito, Anopheles gambiae. Genetics 143, 941-952. 